Vol tammetric el ectrodes modi fi ed wi th swol I en pol yacryl i c I at ex particles

\begin{tabular}{|l|l|}
\hline 著者 & $\begin{array}{l}\text { LI Ti anbao, AOK Koi chi , CHEN Ji ngyuan, } \\
\text { N SH UM Toy ohi ko }\end{array}$ \\
\hline $\begin{array}{l}\text { j our nal or } \\
\text { publ i cat i on titl e }\end{array}$ & Journal of el ect r oanal yt i cal chem st ry \\
\hline year & $2011-$ O4 \\
\hline URL & ht t p: //hdl . handl e. net /10098/3207 \\
\hline
\end{tabular}




\title{
Voltammetric electrodes modified with swollen polyacrylic latex particles
}

\author{
Tianbao Li, Koichi Aoki*, Jingyuan Chen, Toyohiko Nishiumi \\ Department of Applied Physics, University of Fukui \\ 3-9-1 Bunkyo, Fukui, 910-8507 Japan
}

\begin{abstract}
Uniformly sized poly( $N$-isopropylacrylamide-co-acrylic acid) (NIPA/AA) hydrogel particles were synthesized in order to modify an electrode with a carboxyl group-immobilized one-particle layer. They were spheres with a common diameter under given conditions, which ranged from $0.5 \mu \mathrm{m}$ to $1.0 \mu \mathrm{m}$ depending on the $\mathrm{pH}$, ionic concentration and temperature. They were swollen at low salt concentrations, low temperatures and high $\mathrm{pH}$ of aqueous suspensions. One particle contained $6.0 \times 10^{8}$ carboxyl groups, the concentration of which was ca. $1 \mathrm{M}$, exhibiting $\mathrm{p} K_{\mathrm{a}}=5.2$. The particles were adsorbed spontaneously on the platinum surface in a one-particle layer with regular arrangement. The particle-adsorbed electrode showed the voltammetric peak for the reduction of hydrogen ions which were dissociated from the carboxylic groups of the adsorbed layer. The amount of the dissociated hydrogen ions per particle was $19 \%$ of the loaded amount of carboxyl groups, whereas the non-gelized particles had $3 \%$ of the loaded amount. The film worked as a source of supply of hydrogen ions for the electrochemical reduction of 1,4-naphthoquinone. It provided acidic environment of $\mathrm{pH} 4.5$ for the reduction in the neutral solution.
\end{abstract}

Key words: polyacrylic latex particles; hydrogels; dissociation of carboxylic acid; change in volume; modified electrodes

corresponding author, e-mail kaoki@u-fukui.ac.jp (k. Aoki), phone +81 776278665 


\section{Introduction}

Polymer colloids or microparticles have been used for fabricating uniform films on a wide substrate by a spread method [1]. The spread of polymer microparticles has also been applied to modified electrodes, exemplified by polypyrrole colloids [2,3] and polyaniline-polystyrene latex [4]. The latex-modified electrodes have been used for catalysis of nitrite by conducting polymer latex [5], of phenol and catechol by tyrosinase on latex [6], of nitrite by amine- and sulphate-functionalized latex [7], and of heme proteins immobilized on polystyrene latex [8]. Latex particles coated with polyaniline have formed one-particle layer films [9] and self-standing films [10] of electrochemical conversion and corrosion-protected films [11]. Advantages of using latex particles are not only to generate uniform films but also to enhance porosity in films for rapid mass transport. There are two kinds of the porosity, one being vacancy among arranged particles, the other being vacancy within a particle. The former can readily be observed by a microscope, whereas the latter is relevant to polymer structure, depending on synthetic procedures as well as composite structures. The former geometric nonuniformity has been reported for SEM photographs of selective, local dissolution of particles [12,13].

Internal structure of latex participating in mass transport has been investigated by voltammetric analysis of diffusion currents of dispersed latex, especially, of incorporated ferrocenyl derivatives [14-16]. The reacting domains within the particle are restricted to the surface of the particle [15] or extended to the whole particle [16], depending on the polymer structure. Suspended polyaniline-coated latex has been reduced exhaustively because it is conductive enough for maintaining the reduction potential over the whole particle through the conducting zone $[12,17,18]$. The polystyrene-core often blocks electrochemical reactions because ions do not penetrate in 
the core [19-21]. Small, ion-permeable latex might improve drawbacks of the partial reactions and the blocking [8].

A typical ion-permeable polymer is a hydrogel with crosslinking [22]. Some hydrogel particles undergo a reversible, discontinuous volume-change [23] in response to selected stimuli such as $\mathrm{pH}$, salt concentration, temperature and pressure. They have been widely applied to bioengineering [ 24 ] and biotechnology [ 25 ]. Poly( $N$-isopropylacrylamide) gels, abbreviated as PNIPA, exhibit multi-functional responses such as selective release of different solutes [26], protein adsorption resistance [27], and immobilization of nucleic acid probes [28]. Incorporation of carboxyl groups into PNIPA is interesting in medical engineering because the critical temperature of the volume-change is close to the physiological temperature [29]. The charge density in PNIPA has been controlled by the content of acrylic acid (AA), pH, salt concentration [30,31]. Application of the gelation by PNIPA to AA latex is expected to accelerate the dissociation kinetics of carboxyl groups and thus to enhance the $\mathrm{pH}$-control ability. The dissociation properties may be obtained by voltammetry, as have been made previously [20,21,32]. We present here the electrochemical properties of NIPA/AA hydrogel particles in the light of the volume change and dissociation. The result is applied to a source of hydrogen ion in the electrochemical reduction of 1,4-naphthoquinone.

\section{Experimental}

\subsection{Chemicals}

$N$-isopropylacrylamide (NIPA, Wako) was purified by recrystallization twice from hexane/toluene (50/50 v/v). Acrylic acid (AA, Wako) was purified by vacuum distillation. $N, N^{\prime}$-methylenebisacrylamide (MBA, TCI) and 1,4-naphthoquinone (TCI) 
was used as received. (Ferrocenylmethyl)trimethyl-ammonium (FcTMA) hexafluorophosphate was synthesized according to the bibliography [33], and was purified by recrystallization. All the other reagents and solvents were of reagent grade and used as received. Aqueous solutions were prepared with ion-exchanged deionized water of which resistivity was ca. $12 \mathrm{M} \Omega \mathrm{cm}$.

\subsection{Synthesis of poly(N-isopropylacrylamide-co-acrylic acid) hydrogel}

Poly( $\mathrm{N}$-isopropylacrylamide-co-acrylic acid) (NIPA/AA) hydrogel particles were synthesized by one-step surfactant-free emulsion polymerization by a process similar to the documented way [34]. NIPA (126 mM), a cross-linking agent MBA (9 mM) and AA (39 mM) were dissolved in $220 \mathrm{~cm}^{3}$ deionized water in a $500 \mathrm{~cm}^{3}$ round bottom flask equipped with a condenser, a $\mathrm{N}_{2}$ gas inlet, a stirrer and a thermometer. The mixture was stirred at $350 \mathrm{rpm}$ under $\mathrm{N}_{2}$ for $4 \mathrm{~h}$ at room temperature. After the mixture was heated up to $70{ }^{\circ} \mathrm{C}, 30 \mathrm{~cm}^{3}$ of deaerated potassium persulfate $(44 \mathrm{mM})$ was added drop-wise into the mixture to initiate the polymerization. The reaction was continued for $6 \mathrm{~h}$ at $70{ }^{\circ} \mathrm{C}$ under vigorous stirring. After polymerization, the suspension was milky-white, and was purified three times by centrifugation and re-dispersion with deionized water.

\subsection{Instruments}

Cyclic voltammetry was carried out with a potentiostat, Compactstat (Ivium Tech., Netherlands) in a three electrode cell consisting of a platinum disk electrode $1.6 \mathrm{~mm}$ in diameter as a working electrode, an $\mathrm{Ag} \mid \mathrm{AgCl}$ (saturated $\mathrm{KCl}$ ) reference electrode and a platinum coil counter electrode. The surface of the working electrode was polished with $0.03 \mu \mathrm{m}$ alumina paste on a wet cotton cloth. It was rinsed successively with distilled water, acetone, and then 95\% ethanol in a ultrasonic bath. Much care was taken to 
polishing the electrode because the adsorption of the latex was so strong that the electrode was readily contaminated by the used cotton cloth.

The size and geometry of the particles were determined by a scanning electron microscope (SEM, Hitachi, S-2600H). The size was also measured by a dynamic light scattering (DLS, Malvern Zetasizer Nano-ZS) under temperature-control. The DLS measurement for swollen particles was made after 2 days immersion in solutions. Measurements of pH were performed with a Mettler MP 225 meter. A conductometer was HEC-110 (DKK, Tokyo). FTIR spectra were obtained with a Protege 360 (Nicolet) spectrophotometer by the $\mathrm{KBr}$ disk technique. The spectra were corrected against the background spectrum of $\mathrm{KBr}$.

\subsection{Densities}

Densities of the dried $\left(\rho_{\mathrm{d}}\right)$ and the suspended $\left(\rho_{\mathrm{s}}\right)$ particles were evaluated by pycnometry $[35,36]$. The pycnometer was made of glass, ca. $40 \mathrm{~cm}^{3}$ in volume. The accurate volume of the pycnometer was obtained by the subtraction of the weight $\left(m_{\mathrm{b}+\mathrm{w}}\right)$ of the water-filled pycnometer from the weight of the dried one $\left(m_{\mathrm{b}}\right)$. The NIPA/AA suspension at high concentration was filled in the pycnometer and was weighed $\left(m_{\mathrm{b}+\mathrm{s}}\right)$. It was dried in an oven at $90{ }^{\circ} \mathrm{C}$. The cooled pycnometer with the dried NIPA/AA was weighed $\left(m_{\mathrm{b}+\mathrm{d}}\right)$. The difference, $m_{\mathrm{b}+\mathrm{s}}-m_{\mathrm{b}+\mathrm{d}}$, divided by the density of water $\left(\rho_{\mathrm{w}}=0.997\right.$ $\mathrm{g} \mathrm{cm}^{-3}$ ) is the volume of water in the pycnometer. On the other hand, the difference, $m_{\mathrm{b}+\mathrm{d}}-m_{\mathrm{b}}$ divided by the density of the dried particle is the volume of the dried particle in the pycnometer. Heating another suspension at $90{ }^{\circ} \mathrm{C}$ made the particles aggregated to yield a precipitate in water. We filled the pycnometer including the dried particles with water, and weighed it $\left(m_{\mathrm{b}+\mathrm{d}+\mathrm{w}}\right)$. The weight was larger than $m_{\mathrm{b}+\mathrm{d}}$ by the swollen volume. The above measurement of five weights yields the following three equalities for the volume, $V$, of the pycnometer: 
$V=\frac{m_{\mathrm{b}+\mathrm{w}}-m_{\mathrm{b}}}{\rho_{\mathrm{w}}}=\frac{m_{\mathrm{b}+\mathrm{s}}-m_{\mathrm{b}+\mathrm{d}}}{\rho_{\mathrm{w}}}+\frac{m_{\mathrm{b}+\mathrm{d}}-m_{\mathrm{b}}}{\rho_{\mathrm{d}}}=\frac{m_{\mathrm{b}+\mathrm{d}+\mathrm{w}}-m_{\mathrm{b}+\mathrm{d}}}{\rho_{\mathrm{w}}}+\frac{m_{\mathrm{b}+\mathrm{d}}-m_{\mathrm{b}}}{\rho_{\mathrm{s}}}$

Values of five weighs were listed in Table 1 . The densities, $\rho_{\mathrm{d}}$ and $\rho_{\mathrm{s}}$, were calculated from Eq. (1), as listed in Table 1.

\section{Result and discussion}

\subsection{Size of NIPA/AA microgel particles}

Figure 1 shows the FTIR spectrum of NIPA/AA particles. The band at $2975 \mathrm{~cm}^{-1}$ can be assigned to $\mathrm{C}-\mathrm{H}$ stretching vibration, those at 1369 and $1388 \mathrm{~cm}^{-1}$ to two methyl groups on $-\mathrm{C}\left(\mathrm{CH}_{3}\right)_{2}$, that at $1460 \mathrm{~cm}^{-1}$ to $-\mathrm{CH}_{3}$ and $-\mathrm{CH}_{2}$ deformation, those at 1647 and $1545 \mathrm{~cm}^{-1}$ to the typical amide I (-CONH, C=O stretching) and amide II (-CONH, $\mathrm{N}-\mathrm{H}$ bending). The band at $1718 \mathrm{~cm}^{-1}$ can be assigned to the $\mathrm{C}=\mathrm{O}$ stretching vibration of the hydrogen-bonded carboxyl groups of AA $(\mathrm{C}=\odot \mathrm{\Theta O})$ [ 37]. A broad band in the range 3500-3200 $\mathrm{cm}^{-1}$ indicates the presence of hydrogen bond between $\mathrm{N}-\mathrm{H}$ and $\mathrm{O}-\mathrm{H}$ [38]. These bands support partially formation of PIPA/AA.

The aqueous suspensions of NIPA/AA were turbid and stable at least for one month without sedimentation or aggregation. The NIPA/AA particles in the aqueous suspension were spherical and uniform in size from an optical microscope view. The DSL signal of the suspension had a clear band at $1.10 \mu \mathrm{m}$ in diameter. When the particles were purified exhaustively with centrifugation and re-dispersion, the diameter was increased to1.32 $\mu \mathrm{m}$. The increase may be due to electrostatic repulsion by removal of salt, which is a conventional property of hydrogels.

The density of the NIPA/AA particles is required in order to estimate molar concentration of carboxylic acid in one particle from the titrated result. The two densities in Table 1 imply that the swollen particle is composed of water $70 \%$ and 
polymer chains $30 \%$ in volume. The inclusion of water is a clear evidence of the gelation of the NIPA/AA particles.

The Pt electrode was dipped into the suspension, rinsed with water, and dried. The particles were arranged spontaneously on the electrode, as was observed from the optical microscope (Fig. 2). There was no large defect in the arrangement over the electrode except for the edge. A magnification of a defect-included domain (the inset of Fig. 2) indicates that the particles should be adsorbed in a one-particle layer. The diameter averaged over 50 adsorbed particles was $0.56 \mu \mathrm{m}$. The dry particles shrunk by 13 times $\left(=(1.32 / 0.56)^{3}\right)$ in volume because of a loss of water. Their SEM images showed $0.56 \pm 0.013 \mu \mathrm{m}$ in diameter (Fig. 3), where the error means the standard deviation. It exhibits partially ordered arrangement of particles. One particle does not make a contact with neighboring particles but takes some distance with them, as has been observed and explained [39,40,エラー! ブックマークが定義されていませ $\left.h_{\circ}\right]$. The particles were prepared on a glass plate in almost one monolayer form. When the swollen particles dispersed on the glass were dried in vacuum for the SEM measurement, they shrank, keeping their adsorbed points on the glass. When the dried particles were inserted into water and purified, the diameter was recovered to be 1.32 $\mu \mathrm{m}$, suggesting reversible change in size by wetting.

\subsection{Number of carboxyl molecules per one particle}

Conductometric titration was made in order to determine the number of carboxyl molecules loaded on the particle. The NIPA/AA particles, which were acidified with 0.1 M hydrochloric acid, were stirred at room temperature for one day. After the acidified suspension was centrifuged and re-dispersed into distilled water, it was titrated with 19.1 $\mathrm{mM} \mathrm{NaOH}$ solution. The conductance of the titration curve in Fig. 4 did not change until the turning point, as is often found in the weak acid titration [41]. 
Combination of the volume $\left(1.17 \mathrm{~cm}^{3}\right)$ of $\mathrm{NaOH}$ at the turning point and the weight of the loaded dried particles yielded the amount of carboxylic acid, $6.0 \times 10^{8}$ carboxyl molecules per particle or $3.2 \mathrm{mmol}$ (g of the latex) ${ }^{-1}$. If $\mathrm{NaOH}$ were not to be immersed into the center by the hydrophobicity, carboxylic groups near the center of a particle would not be titrated, being left behind the titration. We dissolved the particles in THF and carried out the titration. The titration curve was almost the same as the curve in Fig. 4. Therefore the carboxyl acid within the particles was exhaustively titrated.

The amount of carboxyl groups, $3.2 \mathrm{mmol}$ per g of dried latex can be converted to $3.2 \mathrm{mmol} \times 0.3 \mathrm{~cm}^{-3}=0.96 \mathrm{M}$. This is much larger than the concentration $(0.14 \mathrm{M})$ in copolymer of styrene and acrylate [21]. The NIPA/AA particle can be regarded as a cross-linked microsphere filled with highly concentrated carboxyl acid.

A value of $\mathrm{p} K_{\mathrm{a}}$ of the carboxyl moiety was determined by the $\mathrm{pH}$ titration with the help of the Henderson-Hasselbalch equation. A half equivalence point of the titration curve in Fig. 5 yielded $\mathrm{p} K_{\mathrm{a}}=5.2$. This is close to the value on the polystyrenepolyacrylate latex particles [21], but is larger than those for other carboxyl acids. The larger values may be caused by such high density of deprotonated carboxyl acid that the electrostatic repulsion among - $\mathrm{COO}^{-}$may hinder the dissociation. The electrostatic repulsion has been demonstrated to increase a $K_{\mathrm{a}}$ value [42] for the self-assembled film of $\omega$-carboxylalkanethiol.

\subsection{Change in volume}

Volume-change of the NIPA/AA particles was estimated by means of the DLS in the suspension when temperature, $\mathrm{pH}$, and concentration of salt were varied. The smaller the particle, the sharper the size distribution of DLS signals. This tendency is consistent with formation of hard boundary of the particle. The increase in temperature from 20 to $60{ }^{\circ} \mathrm{C}$ reduced the diameters by $1 / 3$ (not shown), as similar to the reported 
results $[30,43]$. Figure 6 shows the $\mathrm{pH}$ dependence of the diameter at a given ionic strength. The diameter increased with an increase in $\mathrm{pH}$ until 5, which is close to the $\mathrm{p} K_{\mathrm{a}}$ value (5.2). The carboxyl groups at $\mathrm{pH}$ higher than $\mathrm{p} K_{\mathrm{a}}$ are deprotonated so largely that the strong electrostatic repulsion force among them should induce the swelling of the particle. If all the carboxyl groups are assumed to be distributed uniformly within the particles, distances between the neighboring carboxyl groups are calculated to be $0.96 \mathrm{~nm}$ and $1.25 \mathrm{~nm}$ at $\mathrm{pH} 2.5$ and 7.0, respectively.

Effects of salt concentrations on the size were examined in different concentrations of $\mathrm{NaCl}$ solution. When well-deionized suspensions were transferred into 1 and $10 \mathrm{mM} \mathrm{NaCl}$ solutions, the diameters decreased by 0.2 and $46 \%$, respectively. This variation can also be explained by the electric repulsion. The salt concentration dependence on the size was larger than the $\mathrm{pH}$ dependence, because the volume change is ascribed to the ionic interaction.

\subsection{Voltammetry of NIPA/PAA}

The NIPA/AA film-coated electrode was fabricated by dropping $0.1 \mu \mathrm{L}$ suspension $(0.44 \mathrm{~g} / \mathrm{L}, \mathrm{pH} 7)$ on the Pt electrode surface, rinsing the surface with water and by drying the electrode at room temperature. A one-particle layer was readily formed on the Pt electrode, as shown in the inset of Fig. 2 and Fig. 3 as well as in reported document [44]. $\mathrm{N}$-isopropylacrylamide decreases the surface tension so that a thin layer of water including microgel particles can be formed on the electrode. Since particles are within the thin liquid membrane, the formation of the thin layer causes the particles to spread into a monolayer. The particles come closer together due to the capillary interaction as water further evaporated. The capillary force and the interaction may be a driving force of ordering the particles. The other force is adsorption force with which the particles are so strongly adsorbed on the substrate that they can keep a given 
distances each other, independent of the particle-particle interaction $[39,40,45]$. The hydrated layer of particles provided sterical stability and prevented coalescence during the evaporation process. The regular arrangement did no change when the film-coated electrode was immersed in aqueous solutions. In general, latex suspensions and emulsions are adsorbed so strongly even on reference electrodes that the standard potential cannot be maintained $[14,46]$. We added FcTMA to the voltammetric solutions as a standard of the potential. FcTMA plays a role as well in evaluating quantitatively diffusion-controlled currents which might be blocked by films [47].

Voltammetry of the NIPA/AA-coated electrode was made in the aqueous solution including FcTMA and $\mathrm{KCl}$, whose $\mathrm{pH}$ was adjusted with $\mathrm{HCl}$. The voltammogram, as shown in Fig. 7(a), exhibited two pairs of redox waves at $-0.55 \mathrm{~V}$ and $0.45 \mathrm{~V}$. From the comparison with the voltammogram (in Fig. 7(b)) at the bare electrode, the wave at 0.45 $\mathrm{V}$ is due to FcTMA. The potential difference between the anodic peak and the cathodic one near $0.45 \mathrm{~V}$ was $61 \mathrm{mV}$ for the scan rates less than $0.15 \mathrm{~V} \mathrm{~s}^{-1}$. The anodic peak current was only by $2 \%$ less than the cathodic peak current. Both the current values were independent of the film thickness and $\mathrm{pH}$. They were proportional to the square roots of scan rates less than $0.20 \mathrm{~V} \mathrm{~s}^{-1}$. From the slope of the proportionality, the diffusion coefficient of FcTMA was evaluated to be $0.7 \times 10^{-5} \mathrm{~cm}^{2} \mathrm{~s}^{-1}$, which leads to the diameter of FcTMA molecule, $0.7 \mathrm{~nm}$, in water for the viscosity, $0.89 \mathrm{mPa}$. The value of the diffusion coefficient is quite reasonable for FcTMA. There is no blocking effect on the mass transport of FcTMA from the particle film to the electrode surface due to the porous structure of the film and the particle. Because the peak potentials and peak currents of FcTMA at coated electrode were almost the same as those at the bare electrode, the NIPA/AA film has no influence on ion-permeability and mass transport of FCTMA.

The wave at $-0.55 \mathrm{~V}$ may be caused by the reduction of $\mathrm{H}^{+}$dissociated from the carboxyl group in the NIPA/AA. In contrast, the reduction peak of $\mathrm{H}^{+}$was at $-0.40 \mathrm{~V}$ 
for the bare electrode. This potential agreed with the potential of $\mathrm{HCl}$ peak when $\mathrm{pH}$ difference was considered. The potential difference $(0.15 \mathrm{~V})$ between at the latex-coated electrode and latex-coated electrode has been demonstrated to be the dissociation kinetics previously [21]. The identification of the peak at $-0.55 \mathrm{~V}$ can be supported by the approximate proportionality of the peak currents to the scan rates, as shown in Fig. 8. The better approximation by the quadratic equation, $I_{\mathrm{p}}=k_{1} v^{1 / 2}+k_{2} v$, suggests participation not only in adsorption but also in diffusion. The predominance of the adsorption can also be supported by a linear increase in the currents with the loaded amount of the particles. The reduction current of $\mathrm{H}^{+}$at the 40th cycle showed only 5\% decrease from that at the third cycle. The charge of the background-corrected reduction peak was independent of the scan rates. The amount was $41 \mu \mathrm{C}$, which corresponds to $2.5 \times 10^{14} \mathrm{H}^{+}$. The number density of the adsorbed particles was read to be $1.0 \times 10^{3}$ particles $(30 \mu \mathrm{m})^{-2}$ from the photograph in Fig. 2, or $2.2 \times 10^{6}$ particles were loaded on the $1.6 \mathrm{~mm}$ electrode. One adsorbed particle has then $1.1 \times 10^{8}$ dissociated hydrogen ions. This amount corresponds to $0.18 \mathrm{M}$ of carboxyl groups per particle. By comparing it with the loaded amount $(0.96 \mathrm{M})$ of carboxyl molecules by the conductometric titration, $19 \%$ of the loaded amount of carboxyl molecules is dissociated by the electrochemical reduction of $\mathrm{H}^{+}$. This value is larger than the value (3\%) for the polystyrene/poly(acrylic acid) latex [21], because of the high ion-permeability of the gelation. The other $81 \%$ is left behind from the dissociation within particles partly because of insufficient gelation and partly because local blocking of mass transport as has been often found at polymer-modified electrodes [48].

The swelling is predicted to alter the voltammograms of the NIPA/AA-coated electrode, especially due to blocking or immobilization of FcTMA (with + or 2+ charge) by -COO-. Volume-change was made by varying $\mathrm{pH}$ and temperature. However, the peak currents of FcTMA showed no dependence on $\mathrm{pH}$ or temperature. Voltammograms of the anion of $\mathrm{Fe}(\mathrm{CN})^{3-/ 4-}$ did not vary with the swelling as well. In 
contrast, the peak current for the reduction of $\mathrm{H}^{+}$varied with $\mathrm{pH}$. This $\mathrm{pH}$-dependence is not due to the blocking by the swelling but ascribed to a change in a degree of the dissociation.

\subsection{Applications of NIPA/AA-coated electrodes}

The NIPA/AA film is expected to work as a source of supply for hydrogen ion from the carboxyl group with as high as $1 \mathrm{M}$. It may facilitate electrochemical reductions which need a supply of hydrogen ions. We chose 1,4-naphthoquinone as an example of the reductions requiring hydrogen ions. Figure 9 shows the voltammograms of 1,4-naphthoquinone in $\mathrm{KCl}$ solution. A pair of redox waves at $-0.31 /-0.25 \mathrm{~V}$ was observed at the bare Pt electrode (a). The cathodic peak was shifted in the positive direction by $0.2 \mathrm{~V}$ at the NIPA/AA-coated electrode (b). Because addition of $\mathrm{HCl}$ to the solution caused the potential shift (c) at the bare electrode, the shift at the coated electrode should be ascribed to the supply of hydrogen ions from the film. Consequently, the film works as a source of supply of hydrogen ion dissociated from the carboxyl group on demand of electrode reactions near the electrode.

Values of the cathodic peak currents at the bare electrode were the same as those at the coated electrode. They were proportional to the square roots of scan rates less than $0.1 \mathrm{~V} \mathrm{~s}^{-1}$. Therefore they are controlled by diffusion of 1,4-naphthoquinone without detectable dissociation kinetics or blocking of mass transport.

Figure 10 shows the $\mathrm{pH}$ dependence of the cathodic peak potentials of 1,4-naphthoquinone in $\mathrm{KCl}$ solution at bare electrode, exhibiting a linear relationship (a solid line in Fig. 10). The slope was $74 \mathrm{mV} / \mathrm{pH}$ is close to $59 \mathrm{mV} / \mathrm{pH}$ for a reversible hydrogen ion-coupled electron transfer reaction with equal numbers of electrons and protons transferred (a dashed line). The cathodic peak potential of 1,4-naphthoquinone at the NIPA/AA-coated electrode $(-0.13 \mathrm{~V})$ corresponds to $\mathrm{pH} 4.5$ of the solution from 
the arrow in Fig. 10. This $\mathrm{pH}$ value, equivalent to $\left[\mathrm{H}^{+}\right]=0.03 \mathrm{mM}$, is $1 / 5$ of the bulk concentration of 1,4-naphthoquinone. The amount of hydrogen ions required for the reduction of 1,4-naphthoquinone was supplied from the NIPA/AA film.

It is interesting to compare the $\mathrm{pH}$ controllability of the NIPA/AA-coated electrode with that of self-assembled monolayer films by carboxylate [42,49]. It is predicted that the surface density of carboxylate of the NIPA/AA-coated electrode is higher than that of the self-assembled film even if the latter takes closely packed molecular structure. We shall estimate the densities on the assumption of full dissociation without interaction between carboxyl molecules. If the size of a carboxyl group is assumed to be $0.5 \mathrm{~nm}$ [42], the number density of the carboxylate is about $4 \times 10^{12}\left(=\left(10^{6} / 0.5\right)^{2}\right) \mathrm{mm}^{-2}$. In contrast, the NIPA/AA-latex of the wet form has the density, $1 \times 10^{22}(=0.96$ $\left.\mathrm{M} \times 0.19 \times\left(1.32^{3} / 0.0005^{2}\right) N_{\mathrm{A}}\right) \mathrm{mm}^{-2}$. The catalytic effect of NIPA/AA is much larger than the self-assembled films.

\section{Conclusions}

The NIPA/AA hydrogel particles exhibited the densities, $0.30 \mathrm{~g} \mathrm{~cm}^{-3}$ and $0.98 \mathrm{~g}$ $\mathrm{cm}^{-3}$ for the dry and the wet states, respectively. The difference indicates gelation of the particles. One particle contained $6.0 \times 10^{8}$ carboxyl molecules, corresponding to the average concentration $0.96 \mathrm{M}$ of carboxyl groups in wet particles. The value of $\mathrm{p} K_{\mathrm{a}} 5.2$, being larger than that of acetic acid, suggests strong interaction among carboxylic molecules owing to the high concentration. Ion-permeability owing to the gelation caused the dissociation not only from the surface of the particle but also from the inside of the particles.

The particles were adsorbed strongly on the platinum electrode to generate the one-particle layer film. Voltammograms at the NIPA/AA-coated electrode showed cathodic current of $\mathrm{H}^{+}$, which was dissociated from the carboxylic group. The film did 
not blocking the mass transport even at shrunk particles for low $\mathrm{pH}$ due to the high porosity. One-fifth of the loaded carboxyl molecule was dissociated at $\mathrm{pH}$ 4.1. The film worked as a supply of hydrogen ion when hydrogen ion was consumed locally near the electrode. This functionality was applied to the reduction of 1,4-naphthoquinone, the potential of which was shifted with $\mathrm{pH}$ at the Pt electrode. The potential at the NIPA/AA-coated electrode in $\mathrm{pH}$ neutral solution was corresponded to $\mathrm{pH} 4.5$ owing to supply of hydrogen ion from the film.

\section{Acknowledgement}

This work was inspired by Dr. Shaojun Dong's enthusiasm about reactions of nanoparticles. It was financially supported by Grant-in-Aid for Scientific Research (C) 22550072. 


\section{Figure Captions}

Fig. 1. FTIR spectrum of NIPA/AA.

Fig. 2. Photograph of NIPA/AA mono-particle layer on Pt electrode surface by an optical microscope. The inset is a magnification of a defect-included domain.

Fig. 3. SEM image of NIPA/AA mono-particle layer on a glass plate.

Fig. 4. Conductometric titration curve of $0.35 \mathrm{~g} \mathrm{dm}^{-3}$ NIPA/AA suspensions $\left(20 \mathrm{~cm}^{3}\right)$ by 19.1 $\mathrm{mM} \mathrm{NaOH}$, where $V_{\mathrm{NaOH}}$ was the titrated volume.

Fig. 5. pH-Titration curve of $0.35 \mathrm{~g} \mathrm{dm}^{-3}$ NIPA/AA suspensions $\left(20 \mathrm{~cm}^{3}\right)$ including 0.1 $\mathrm{M} \mathrm{KCl}$ against titrated volume of $19.1 \mathrm{mM} \mathrm{NaOH}$.

Fig. 6. $\mathrm{pH}$ dependence of diameters of NIPA/AA microgel particles at $25^{\circ} \mathrm{C} . \mathrm{pH}$ was controlled by using acetate $(\mathrm{pH}$ 2.6-5.4) and $0.1 \mathrm{M}$ phosphate $(\mathrm{pH}$ 6.0-7.0) buffer solutions.

Fig. 7. Voltammograms of $0.08 \mathrm{mM} \mathrm{HCl}+0.14 \mathrm{mM}$ FcTMA $+0.15 \mathrm{M} \mathrm{KCl}$ at (a) the NIPA/AA-coated and (b) the bare electrodes for $v=0.1 \mathrm{~V} \mathrm{~s}^{-1}$.

Fig. 8. Plots of the peak currents at $-0.55 \mathrm{~V}$ in Fig. 7 against scan rates on the lower axis and their square-roots on the upper axis.

Fig. 9. Voltammograms of $0.16 \mathrm{mM}$ 1,4-naphthoquinone $+0.15 \mathrm{M} \mathrm{KCl}$ at (a) the bare, and (b) NIPA/AA-coated electrodes. Addition of $1 \mathrm{mM} \mathrm{HCl}$ yielded curve (c) at the bare electrode. 
Fig. 10. The $\mathrm{pH}$ dependence of the cathodic peak potential of 1,4-naphthoquinone at the Pt electrode. Solid line is the experiment result; dot line is the ideal value for slope 59 $\mathrm{mV} / \mathrm{pH}$. 


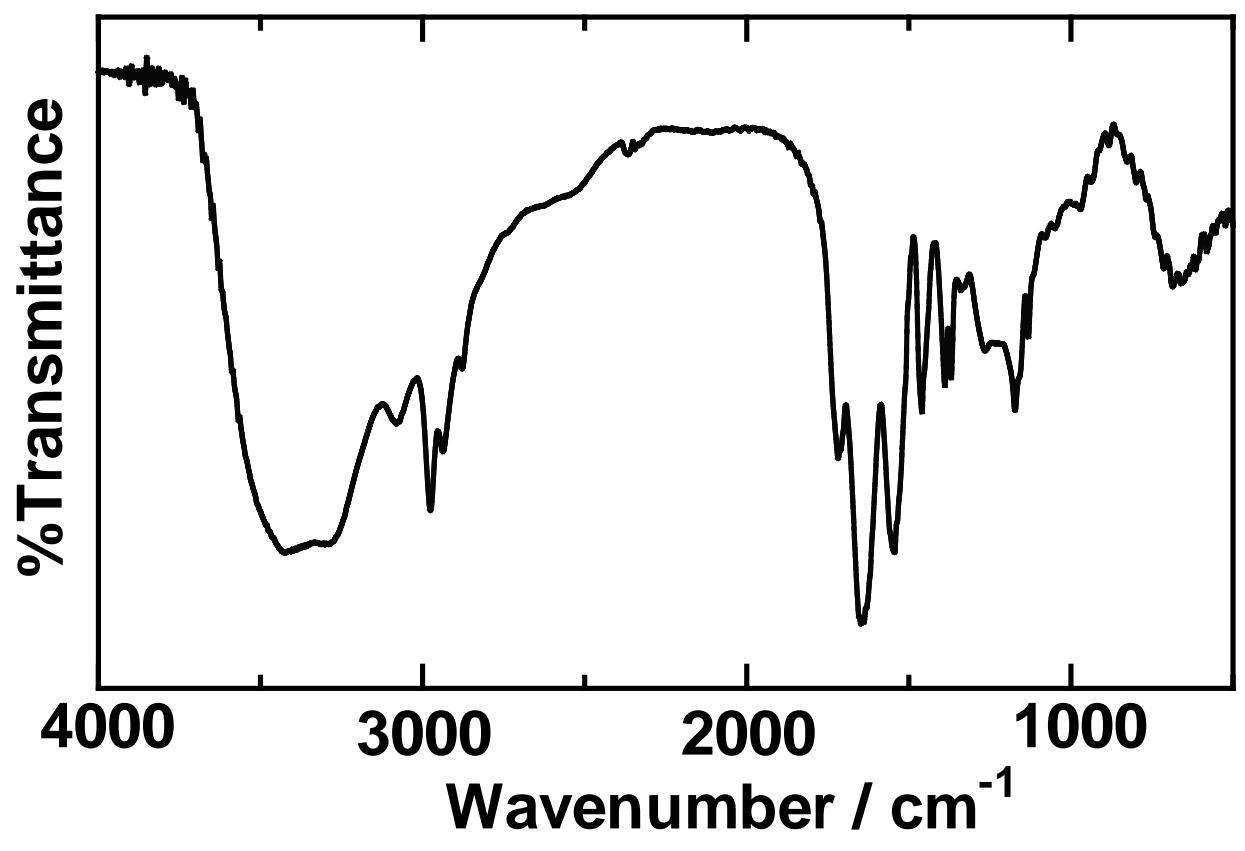

Figure 1

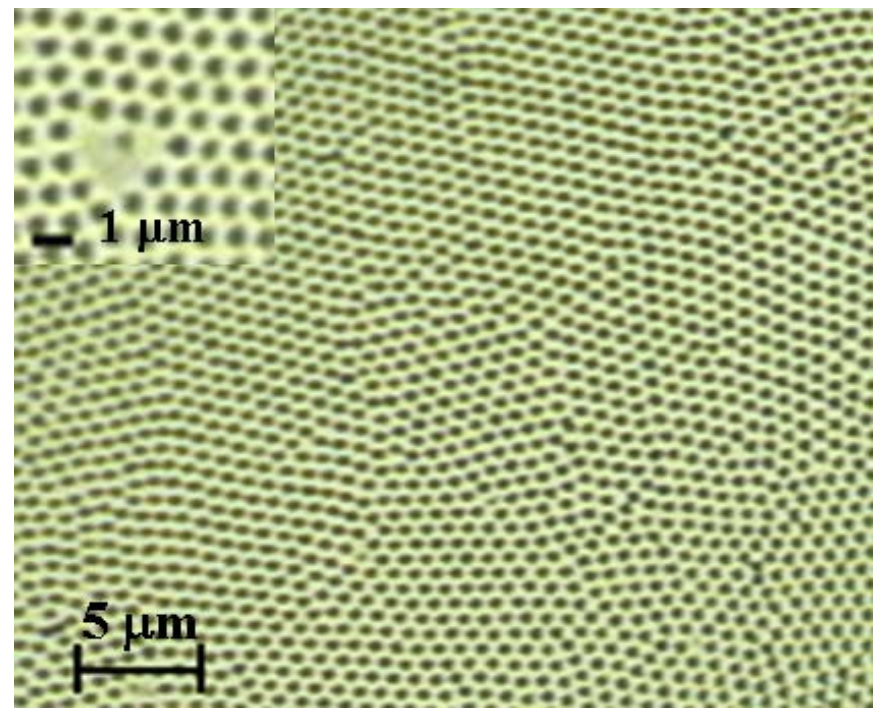

Figure 2 


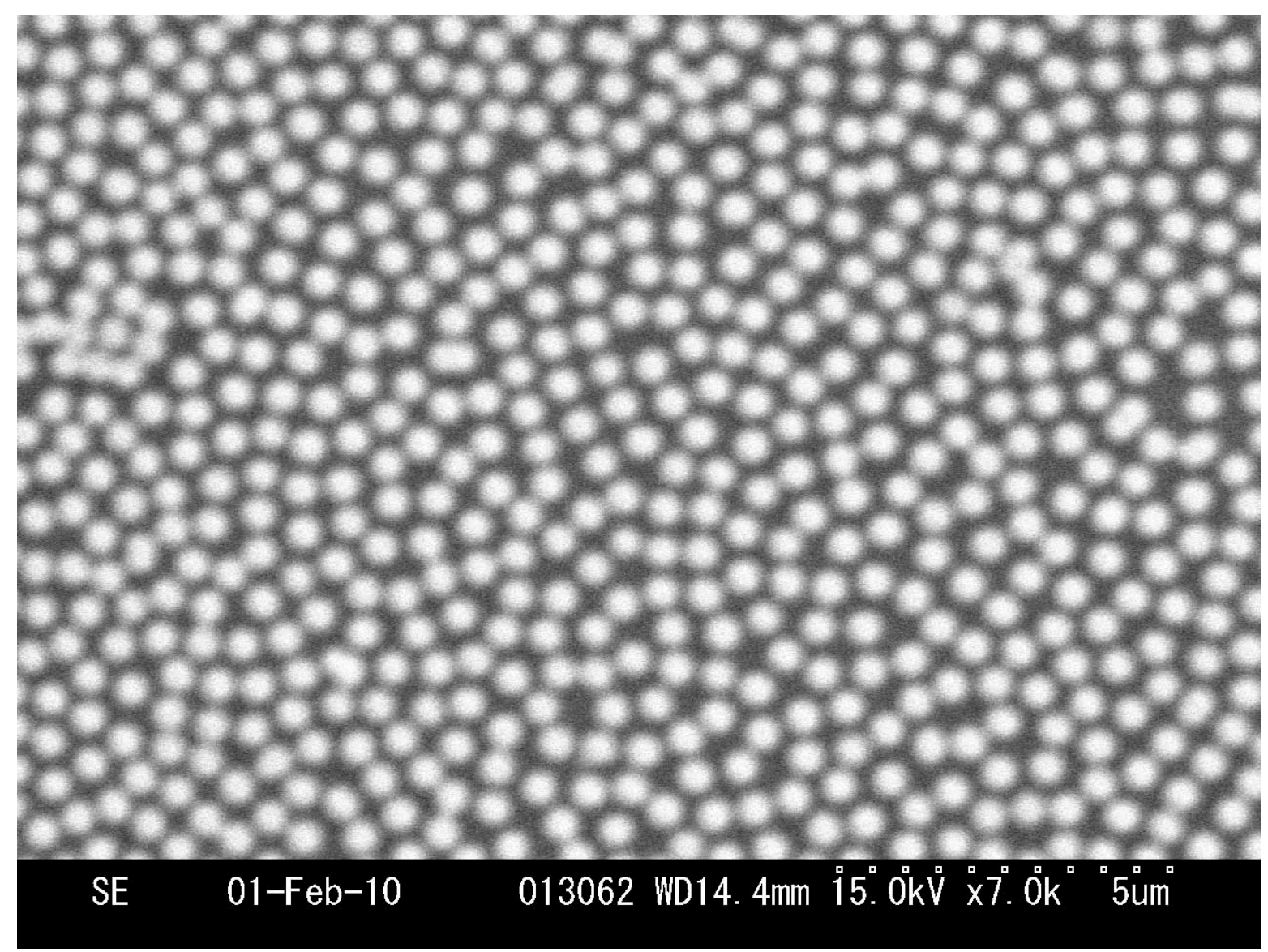

Figure 3

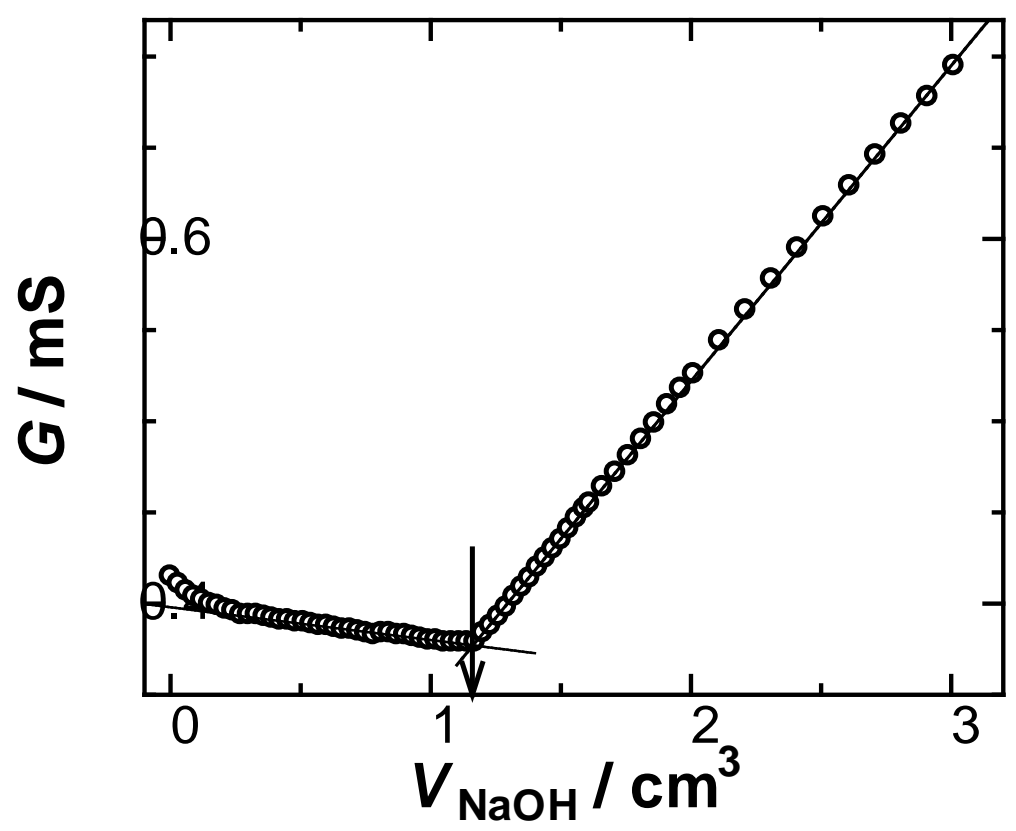

Figure 4 


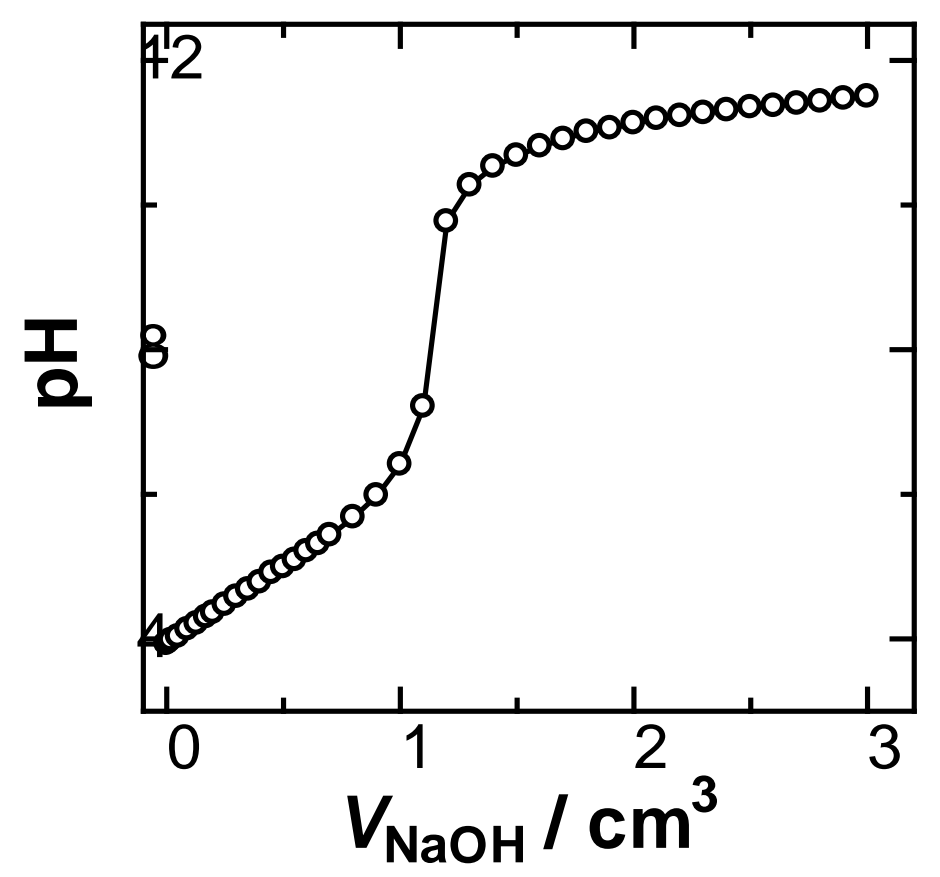

Figure 5

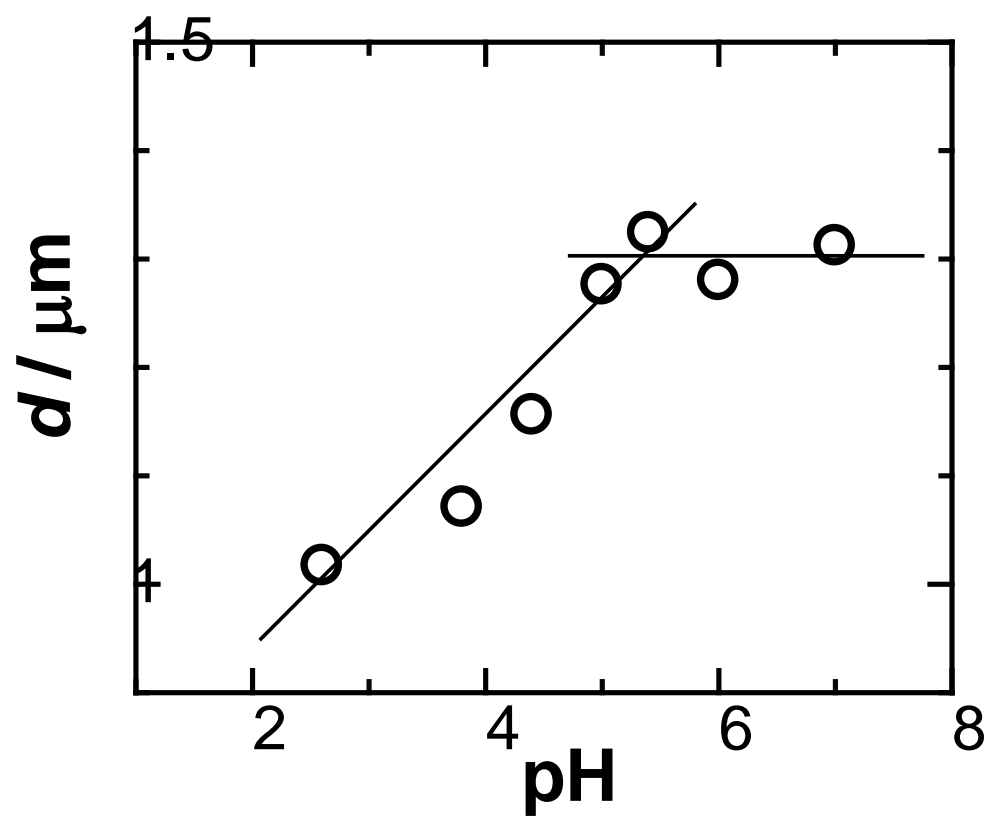

Figure 6 


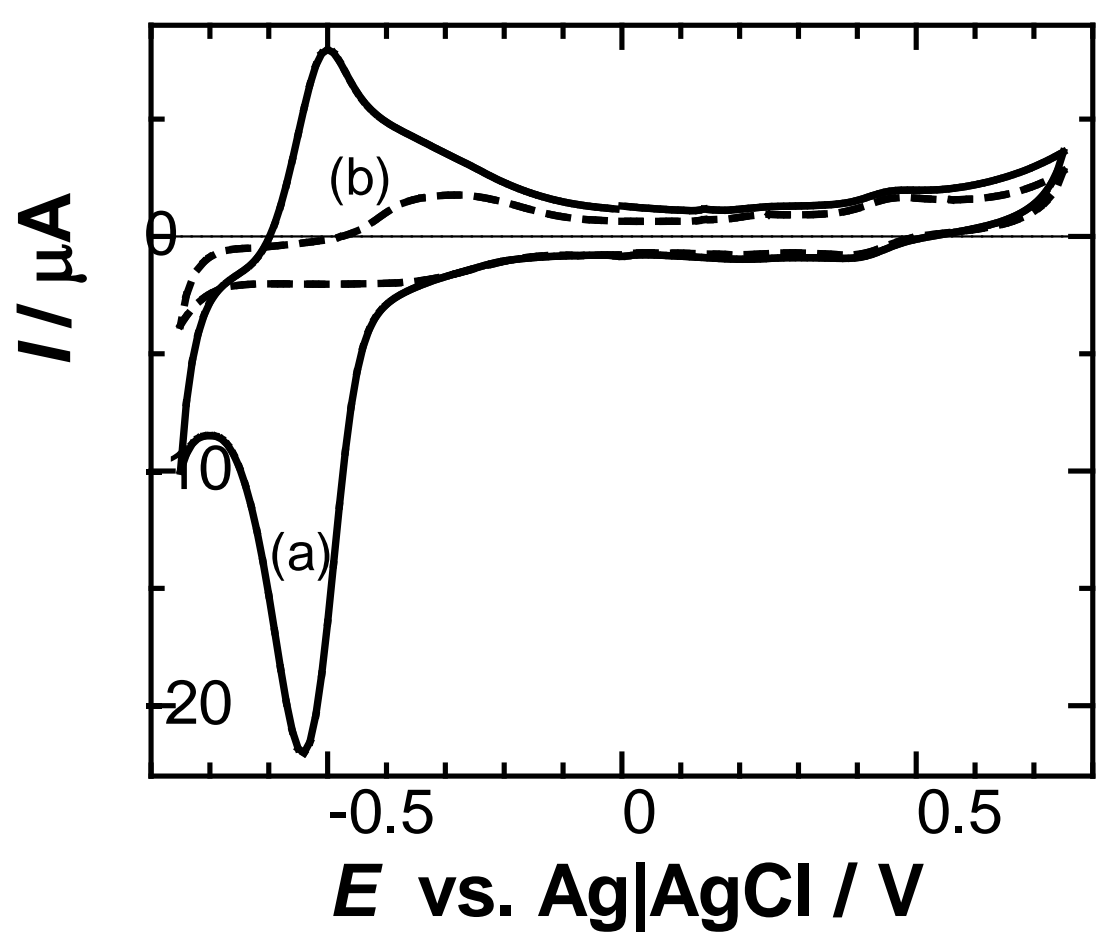

Figure 7

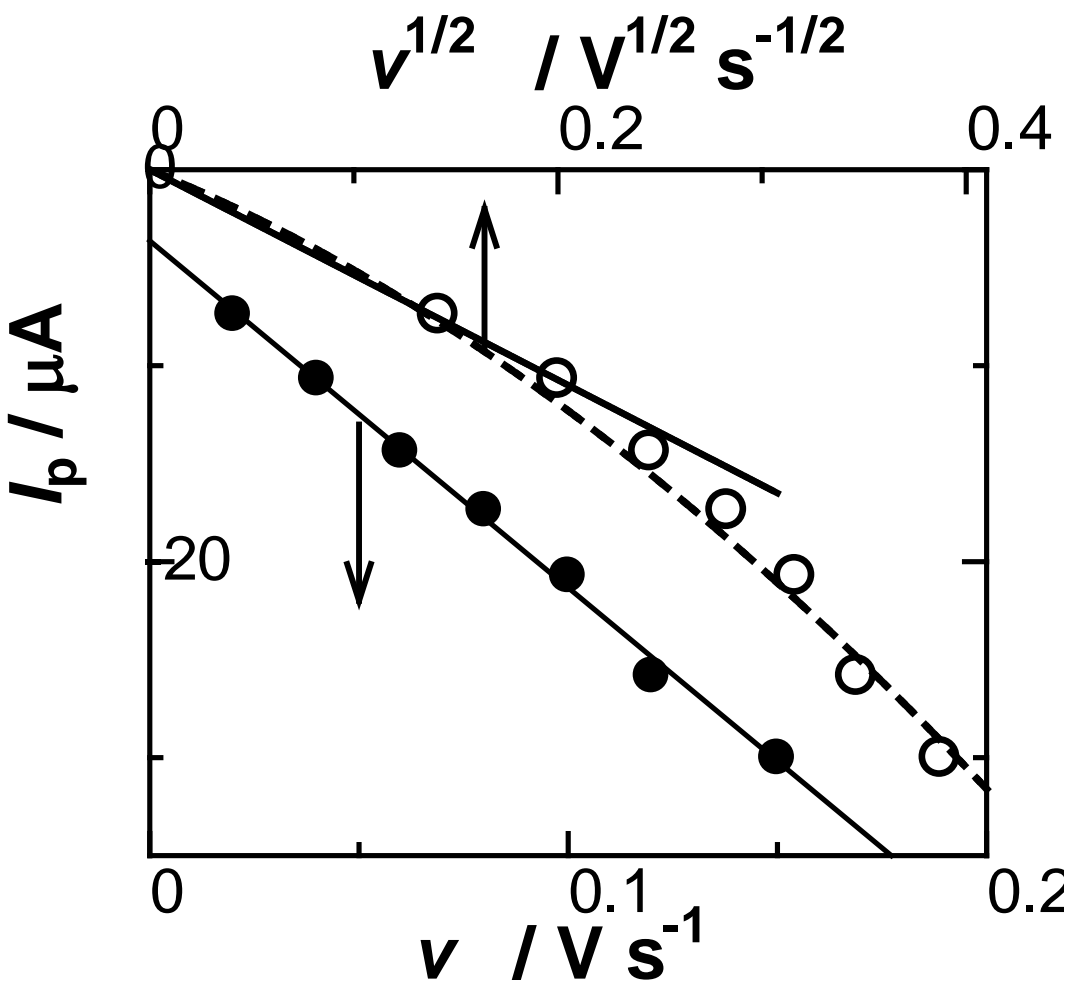

Figure 8 


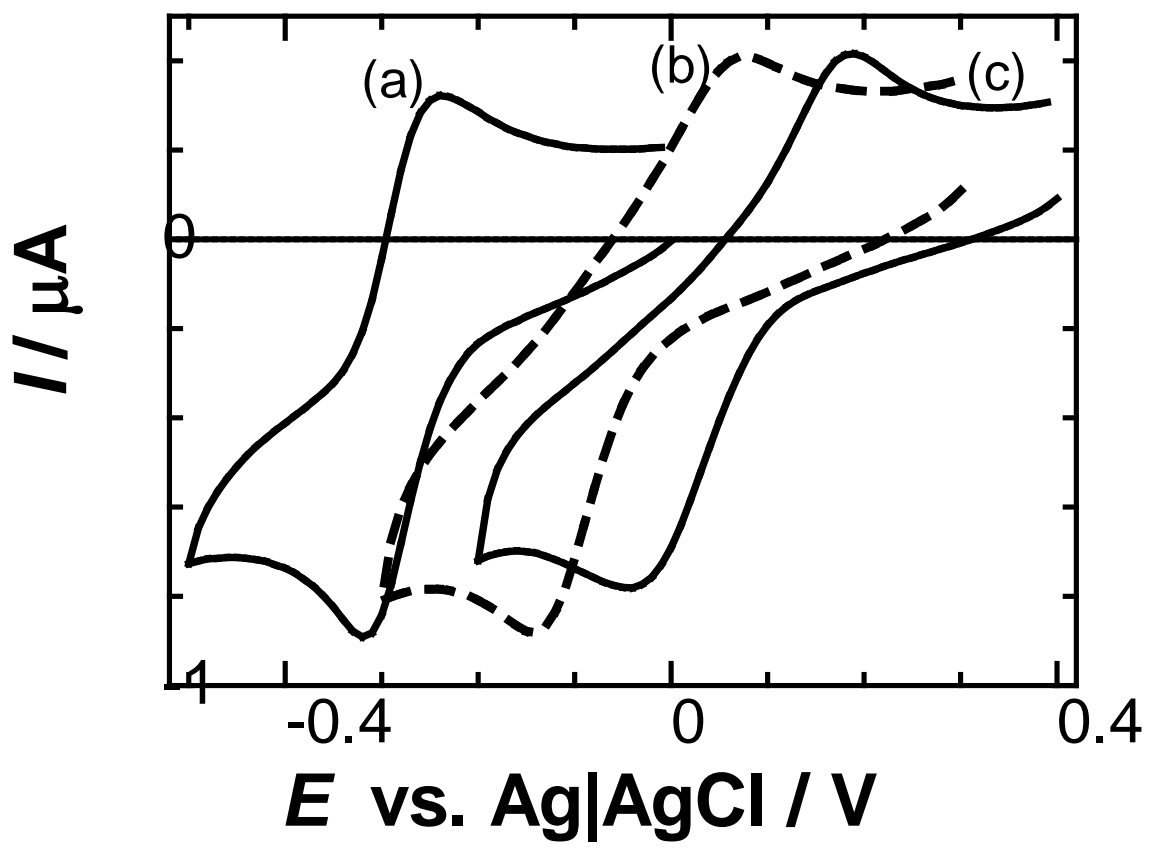

Figure 9

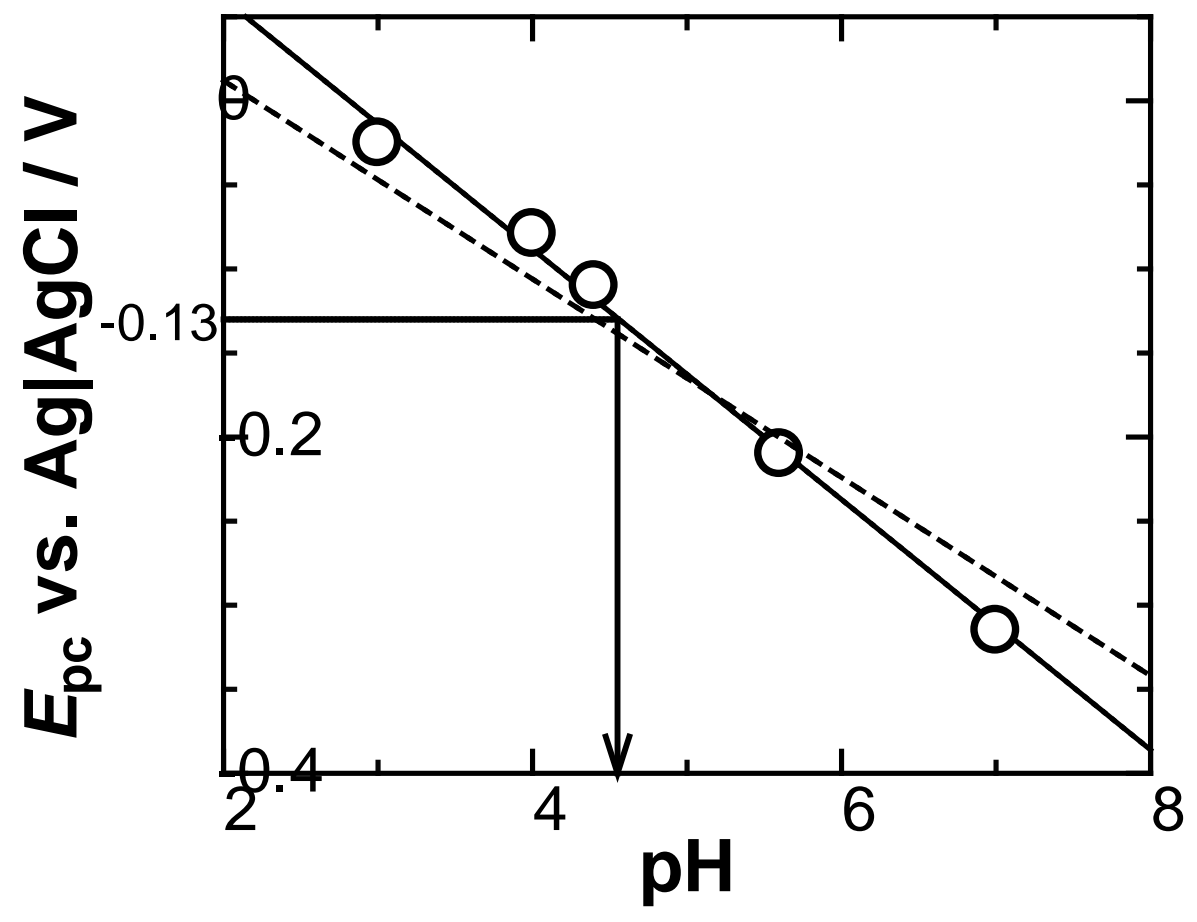

Figure 10 
Table 1 Weights of pycnometer and evaluated densities of the latex

\begin{tabular}{|l|l|}
\hline$m_{\mathrm{b}}$ & $35.539 \mathrm{~g}$ \\
\hline$m_{\mathrm{b}+\mathrm{w}}$ & $79.622 \mathrm{~g}$ \\
\hline$m_{\mathrm{b}+\mathrm{s}}$ & $79.276 \mathrm{~g}$ \\
\hline$m_{\mathrm{b}+\mathrm{d}}$ & $35.688 \mathrm{~g}$ \\
\hline$m_{\mathrm{b}+\mathrm{d}+\mathrm{w}}$ & $79.619 \mathrm{~g}^{-3}$ \\
\hline$\rho_{\mathrm{d}}$ & $0.30 \mathrm{~g} \mathrm{~cm}^{-3}$ \\
\hline$\rho_{\mathrm{s}}$ & $0.98 \mathrm{~g} \mathrm{~cm}^{-3}$ \\
\hline
\end{tabular}




\section{References}

[1] S. Kiil, Progr. Org. Coating. 57 (2006) 236.

[2] C. G. J. Koopal, M. C. Feiters, R. J. M. Nolte, B. De Ruiter, R. B. Schasfoort, Bioelectrochem. Bioenerg. 29 (1992) 159.

[3] C. Yang, S. Dong, Collid. Polym. Sci. 275 (1997) 953.

[4] Y. Liu, X. Feng, J. Shen, J.J. Zhu, W. Hou, J. Phys. Chem. B 112 (2008) 9237.

[5] X. Luo, A. J. Killard, M. R. Smyth. Chem. Eur. J. 13 (2006) 2138.

[6] P. Rijiravanich, K. Aoki, J. Chen, W. Surareungchai, M. Somasundrum, J. Electroanal. Chem. 589 (2006) 249.

[7] M. Muchindua, T. Waryoa, O. Arotiba, E. Kazimierska, A. Morrin, A. J. Killard, M. R. Smyth, N. Jaheda, B. Kgarebe, P. G. L. Baker, E. I. Iwuoha, Electrochim. Acta 55 (2010) 4274.

[8] H. Sun, N. Hu, J. Electroanal. Chem. 588 (2006) 207.

[9] Y. M. Abu, K. Aoki, J. Electroanal. Chem. 565 (2003) 219.

[10] Y. M. Abu, K. Aoki, Electrochim. Acta, 50 (2005) 3634.

[11] Y. M. Abu, K. Aoki, J. Electroanal. Chem. 583 (2005) 133.

[12] K. Aoki, J. Chen, Q. Ke, S. P. Armes, D. P. Randall, Langmuir 19 (2003) 5511.

[13] M. A. Khan, S. P. Armes, Langmuir 15 (1999) 3469.

[14] C. Xu, J. Chen, K. Aoki, Electrochem. Commun. 5 (2003) 506.

[15] C. Xu, K. Aoki, Langmuir 20 (2004) 10194.

[16] L. Han, J. Chen, K. Aoki, J. Electroanal. Chem. 602 (2007) 123.

[17] K. Aoki, Q. Ke, J. Electroanal. Chem. 587 (2006) 86.

[18] H. Chen, J. Chen, K. Aoki, T. Nishiumi, Electrochim. Acta, 53 (2008) 7100.

[19] J. Chen, C. Xu, K. Aoki, J. Electroanal. Chem. 546 (2003) 79.

[20] K. Aoki, T. Li, J. Chen, T. Nishiumi, J. Electroanal. Chem. 613 (2008) 1. 
[21] T. Li, K. Aoki, J. Chen, T. Nishiumi. J. Electroanal. Chem. 633 (2009) 319.

[22] K. Dusek, D. Patterson, J. Polym. Sci., Polym. Phys. Ed. 6 (1968) 1209.

[23] T. Tanaka, Phys. Rev. Lett. 40 (1978) 820.

[24] R. V. Ramanujan, K. L. Ang, S. Venkatraman, J. Mater. Sci. 44 (2009)1381.

[25] H. Kawaguchi, Prog. Polym. Sci. 25 (2000) 1171.

[26] I. Lynch, P. Gregorio, K. A. Dawson. J. Phys. Chem. B. 109 (2005) 6257.

[27] D. Gan, L. A. Lyon, Macromolecules, 35 (2002) 9634.

[28] T. Delair, F. Meunier, A. Elaissari, M. -H. Charles, C. Pichot. Colloids Surf. A. 153 (1999) 341.

[29] M. Shibayama, S. Mizutani, S. Nomura, Macromolecules, 29 (1996) 2019.

[30] K. Kratz, T. Hellweg, W. Eimer, Colloids Surf. A, 170 (2000) 137.

[31] T. Hoare, R. Pelton, Langmuir, 20 (2004) 2123.

[32] J. H. A. M. Monders, H. P. Van Leeuwen, Electrochim. Acta 43 (1998) 3401.

[33] E. J. Calvo, A. Wolosiuk, J. Am. Chem. Soc. 124 (2002) 8490.

[34] G. E. Morris,B. Voncent, M. J. Snowden, J. Colloid Interface Sci. 190 (1997) 198.

[35] I. Janotka, L. Krajci, Chem. Pap. 58 (2004) 79.

[36] T. Tokuhiro, J. Phys. Chem. B, 103 (1999) 7097.

[37] Y. Hirashima, H. Sato, A. Suzuki, Macromolecules, 38 (2005) 9280.

[38] T. Caykara, S. kipper, G. Demirel, S. Demirci, C. Cakanyıldırım, Polym. Int., 56 (2007) 275.

[39] R. H. Pelton, P. Chibante, Colloids Surf. 20 (1986) 247.

[40] R. H. Pelton, Adv. Colloid Interface Sci. 85 (2000) 1.

[41] T. Hoare, R, Pelton, Langmuir, 22 (2006) 7342.

[42] K. Aoki, T. Kakiuchi, J. Electroanal. Chem. 478 (1999) 101.

[43] D. Huo, Y. Li, Q. Qian, T. Kobayashi, Colloids Surf. B, 50 (2006) 36.

[44] S. Tsuji, H. Kawaguchi, Langmuir 21 (2005) 2434.

[45] S. Tsuji, H. Kawaguchi, Langmuir, 21 (2005) 8439. 
[46] J. Yoshida, J. Chen, K. Aoki, J. Electroanal. Chem. 553 (2003) 117.

[47] K. Aoki, J. Chen, Z. Hua, J. Electroanal. Chem. 610 (2007) 211.

[48] K. Aoki, K. Tokuda, H. Matsuda, N. Oyama, J. Electroanal. Chem. 176 (1984) 139.

[49] D. Hobara, M Miyake, S. Imabayashi, K. Niki, T. Kakiuchi, Langmuir, 14 (1998) 3590 . 